\title{
Estado e transição na tradição marxista: formas políticas para pensar a atualidade
}

\section{State and transition in the marxist tradition: political forms to think about the present}

\author{
Marcus Paulo Eiffle Duarte \\ (D) https://orcid.org/0000-0002-0026-4896 \\ Patrícia Baptista Barreto ${ }^{a}$ \\ (D) https://orcid.org/0000-0002-0342-4306 \\ Luci Faria Pinheiro ${ }^{a}$ \\ (D) https://orcid.org/0000-0001-9112-0670
}

Resumo: Buscou-se a concepção de Estado e sua alternativa na tradição marxista para uma reflexão das possibilidades de transformação da realidade atual conjuntamente com a teoria da transição de Mészáros, já que apesar do progresso econômico persiste o subdesenvolvimento social. Conclui-se que a democratização da forma política atual é um caminho para a transformação e que a crise proporciona uma janela de oportunidades para novas concepções políticas.

Palavras-chaves: Estado. Tradição marxista. Transição.
Abstract: The concept of State and its alternative in the Marxist tradition were sought to reflect on the possibilities of transforming the current reality together with Mészáros' theory of transition, since despite economic progress, social underdevelopment persists. It is concluded that the democratization of the current political form is a path to transformation, and that the crisis provides a window of opportunity for new political conceptions.

Keywords: State. Marxist tradition. Transition. 


\section{Introdução}

$\mathrm{N}$ osso objetivo é fornecer elementos para uma compreensão das transformações possíveis da sociedade atual a partir da concepção de Estado e a alternativa a este na tradição marxista para se pensar as formas políticas que podem ser elaboradas pela democracia.

Pode-se considerar que a sociedade brasileira encontra-se integrada em um sistema capitalista mundial, no qual sua posição ainda é periférica e dependente. Apesar de uma forma política democrática retomada desde 1985, a melhora das condições sociais quanto à sua abrangência e diversidade é notoriamente restrita. $O$ desemprego, a fome, a violência e a degradação ambiental são, por exemplo, questões prementes que poderiam caracterizar o insucesso relativo de algumas de nossas principais políticas públicas ou mesmo das formas políticas institucionalizadas, as quais contêm a democracia de tipo representativa. Daí, uma das perguntas que nos fazemos é se é possível se obter uma maior democratização da democracia dentro das características fundacionais do Estado atual, o qual, na concepção marxista clássica, é instrumento de poder político coercitivo e ideológico majoritariamente das classes apropriadoras do excedente social.

A primeira seção explora a concepção marxista de Estado como Estado burguês e, também, a de um "meio Estado" proletário em Marx e Lenin, especialmente. A segunda seção introduz a teoria da transição de Mészáros, propondo que a disputa democrática deve se referir também à sua própria expansão como forma política, mesclando representatividade com mais participação direta via conselhos. As considerações finais resumem um entendimento do Estado e de sua alternativa, segundo a tradição marxista, e sugerem que a luta democrática passa pelo alargamento das próprias condições atuais de tipo representativa e que a crise desempenha um papel de abertura de oportunidades para novas concepções políticas. 


\section{Estado ou transição na tradição marxista: formas políticas}

Na tradição marxista clássica - aquela que faz a crítica da economia política da sociedade do capital e conclui no sentido de superação dessa sociedade necessariamente por meio de uma revolução contra os donos do capital, em razão da exploração do trabalho e seus amplos efeitos perversos sobre a sociedade -, o Estado Absolutista foi uma consequência da servidão que preponderou durante a Idade Média, ou seja, do arranjo socioeconômico entre as classes, imposto pela força econômica, política e ideológica das classes dominantes, assim como o Estado Burguês atual é consequência do desenvolvimento dos mercados, da propriedade privada, do trabalho livre assalariado e da industrialização como idealizações evolutivas da humanidade, no sentido mesmo de progresso - o qual é uma atribuição do pensamento ou da ideologia classificada por nós como liberal.

A tradição marxista a que nos referimos está basicamente referenciada, além do próprio Marx, em Engels, Lenin, Trotsky e Gramsci. Lenin nos parece ter sido um dos mais fiéis seguidores das conclusões marxianas e provou isso, por exemplo, em 0 Estado e a revolução, obra que precede o redirecionamento de outubro da Revolução Russa de 1917 e sintetiza a noção de Estado até então entre Marx, Engels e Lenin, excluindo-se Gramsci, propondo a transição do capitalismo ao socialismo quanto à forma política que devia ser assumida. O caráter burguês ou liberal da deposição do czar no seu primeiro evento revolucionário de 1917, em fevereiro, é então substituído pela orientação bolchevique, da qual Lenin era uma das grandes lideranças levando em conta o movimento comunista.

A questão do Estado envolve as preocupações do líder bolchevique, as quais o percebem como fomentador da Guerra Mundial que eclodiu em 1914 sob a configuração de uma guerra imperialista, transformando o capitalismo monopolista em um capitalismo monopolista de Estado (Lenine, [19--], p. 5). Está assim tratado o caráter ruinoso do imperialismo estatal como uma disputa de nações por mercados e hegemonia. 


\subsection{Marx e o Estado}

Nos escritos marxianos de análise mais política, podemos colher percepções quanto ao Estado, à democracia, ao parlamento, além de menções menos frequentes ao comunismo como sua forma política de transição: a ditadura do proletariado. A sociedade comunista é projetada em duas fases, a primeira é a de transição e conserva a necessidade de algum poder central e coercitivo, o qual, entretanto, perderá essas características no decorrer das novas relações produtivas, não mais baseadas na apropriação privada do trabalho social, o que marcaria o ingresso na segunda fase.

Na primeira fase da sociedade comunista (socialismo), há uma concepção de Estado proletário com instituições e necessidades elaboradas a partir da forma política revolucionária da ditadura do proletariado. É só na fase superior da sociedade comunista que o Estado, assim como a democracia, ainda que na sua forma mais completa, desaparece. Essas formas políticas precisam esgotar-se para que a liberdade e a emancipação do trabalho acabem definitivamente com a opressão de uma classe sobre a outra, nem que seja a opressão de fato da maioria sobre a minoria (Lenine, [19--], p. 93-94).

Ao analisar a Comuna de Paris em 1871, na forma de um comunicado oficial da AIT (Associação Internacional dos Trabalhadores), Marx reconhece o parlamento francês, após a Revolução de 1789, "sob o controle direto das classes possuidoras", como um "viveiro de enormes dívidas nacionais e de impostos esmagadores", o qual seduz com seus "cargos, proteções e empregos", e que assim "acabou por ser a maçã da discórdia entre as facções rivais e os aventureiros das classes dominantes" (Marx, 1999, p. 85).

Após cada revolução, cada conflito entre classes, notadamente a Primavera dos Povos de 1848, Marx (1999, p. 86) diz que é evidenciado o "caráter puramente repressivo do poder do Estado", daquele Estado que se quer de inspiração liberal. Marx (1999, p. 84) alerta que a "classe operária não pode limitar-se simplesmente a se apossar da máquina do estado tal como se apresenta e servir-se dela para seus próprios fins". Anteriormente à Revolução Francesa, o exército permanente, a polícia, a burocracia, o 
clero, a magistratura já haviam sido instituições herdadas dos tempos do Absolutismo e serviram, em alguma medida, à nascente sociedade burguesa contra o regime de servidão feudal - Marx nos explica. $\mathrm{O}$ desenvolvimento dessa sociedade burguesa, entretanto, "foi entravado por todo tipo de rebotalhos medievais: direitos senhoriais, privilégios locais, monopólios municipais e corporativos, códigos provinciais" (Marx, 1999, p. 84-85). Apenas a "escova gigantesca" da revolução de fins do século XVIII "varreu todas essas relíquias", dando azo a que pudesse se erguer de vez "a superestrutura do edifício do Estado moderno" (Marx, 1999, p. 85).

Ao dizer que a Comuna "devia ser, não um órgão parlamentar, mas uma corporação de trabalho, executiva e legislativa ao mesmo tempo" (Marx, 1999, p. 89), fica claro em Marx sua incredulidade quanto à forma política republicana burguesa que separa poderes, como o legislativo e o executivo.

Marx (1999, p. 95) chega a mencionar uma das conquistas implementadas pela Comuna como uma das reivindicações das "revoluções burguesas, que é um 'governo barato' ao destruir os dois grandes fatores de gastos: o exército permanente e a burocracia do Estado”. Observando ainda temas que preocupam diferentes segmentos da sociedade até hoje pela natureza de seu comportamento, como a criminalidade e a prostituição, Marx (1999, p. 108) chega a afirmar que:

Paris já não era o rendez-vous de latifundiários ingleses, dos absenteístas irlandeses, antigos escravistas e mercenários norte-americanos, ex-proprietários russos de servos e boiardos de Valáquia. Já não havia cadáveres no necrotério, nem assaltos noturnos, nem simples furtos. Pela primeira vez desde os dias de fevereiro de 1848, podia-se andar pelas ruas de Paris, e isso sem que existisse polícia de nenhuma espécie.

Ainda em 1875, Marx (2012, p. 44) continua seu testemunho implacável contra as reivindicações de um modelo de "república democrática de um Estado que não é mais do que um despotismo militar com armação burocrática e blindagem policial, enfeitado de formas parlamentares, 
misturado com ingredientes feudais e, ao mesmo tempo, já influenciado pela burguesia".

Estão esboçados aqui tanto o (i) caráter do Estado, como meio de dominação e de degradação social, quanto a (ii) consequente necessidade da revolução, como único instrumento de destituição da dominação coercitiva e da direção ideológica. No caso pretendido por Marx, para a construção de uma nova superestrutura que favoreça a classe proletária. Sem a destruição ou a abolição da máquina de Estado burguesa, em outras palavras, da forma política que se institucionaliza e condiciona as relações sociais, não se pode erigir uma nova forma política que favoreça as classes não possuidoras dos meios de produção.

O Estado marxiano, porém, próprio de seu tempo, especialmente na Europa, ainda tem os "ingredientes feudais", não são ainda as repúblicas democráticas mais avançadas do centro da economia capitalista a partir da segunda metade do século XX. Uma questão a ser respondida seria: livres dos traços feudais, essas repúblicas mais avançadas expressam realmente a vontade ou os interesses da maioria, ou o poder econômico ainda concentra a maior parte do poder estatal através de sua forma política burguesa de democracia representativa?

No caso de a resposta ser negativa quanto à expressão da vontade da maioria, poderíamos considerar que é a própria democracia representativa que se apresenta insuficiente como forma política de organização e gestão societária.

Marx (1999, p. 95-96) atesta que a Comuna foi uma "forma política perfeitamente flexível". O seu "verdadeiro segredo" foi ser um "governo da classe operária, fruto da luta da classe produtora contra a classe apropriadora, a forma política afinal descoberta para levar a cabo a emancipação econômica do trabalho". Marx (1999, p. 95-96) diz que "uma vez emancipado o trabalho, todo homem se converte em trabalhador, e o trabalho produtivo deixa de ser um atributo de classe". Ainda assim, para uma ciência empírica, os pouco mais de 60 dias da experiência comunal talvez não cheguem para permitir tais considerações. Haveria aqui um tom panfletário, que não deixa de ser necessário à causa revolucionária, 
ou até uma determinação lógica, embora não empírica, preocupada com o futuro dos desdobramentos comunais, notem-se os desvios e os perigos do comunismo da antiga União das Repúblicas Socialistas Soviéticas (URSS) deflagrado especialmente pelo período stalinista (Trotsky, 1980; Hobsbawm, 1998), todavia não é o centro de nossa discussão.

De qualquer modo, parte dessa "forma política afinal descoberta" passa pela eleição de um número limitado de representantes da Comuna, os delegados ou deputados, embora sob condições como as de serem demissíveis a qualquer momento e de não receberem pagamento maior que o de um operário. Esses representantes compunham comissões, como as de finanças ou de guerra, as quais ainda tinham que se dirigir a outros grupos de representação dos comunardos (Boito Jr., 2002; Merriman, 2015), o que estimula configurarmos aquela democracia como de novo tipo, como atestou Lenin, com participação direta via conselhos. Para nós, outras decisões tomadas naquele curto espaço de tempo pela Comuna atestam seu caráter progressivo e emancipador, corroborando o entusiasmo de Marx com o futuro da Comuna.

\subsection{Marx e o comunismo}

Vimos algumas das principais preocupações marxianas de se viver em uma sociedade capitalista. Assim, os ganhos de forçar a transição, mesmo que por via revolucionária para uma sociedade de tipo socialista, poderiam compensar e recompensar a práxis humana voltada para tal fim.

Do exame concreto da experiência da Comuna à Crítica do programa de Gotha, escrita quatro anos depois, em 1875, a forma política de um Estado proletário futuro é um pouco mais desenhada. Assim, ao criticar equívocos e imprecisões quanto a uma práxis voltada para a transição comunista constante do programa que uniria os dois grandes partidos do proletariado alemão, Marx o faz buscando certo rigor ao falar de propósitos e condições para uma primeira fase da sociedade comunista, o que o fez projetar noções realistas de um socialismo contra Bakunin e seus anarquistas e contra os socialistas liderados por Ferdinand Lassalle (Löwy, 2012; Engels, 2012). 
Marx (2012, p. 28-33) toca na questão do que poderíamos abordar hoje como fundos públicos, salários e distribuição ao explorar a redação do programa no tocante à "distribuição justa do fruto do trabalho" e "o fruto do trabalho pertence inteiramente, com igual direito, a todos os membros da sociedade". Essa passagem se torna esclarecedora do ponto de vista marxiano sobre os modos que podemos traduzir como de custeio e investimento aquelas necessidades da produção, assim como de serviços essenciais à coletividade, além de formular uma noção de justiça social quanto à distribuição ou redistribuição do "produto social".

Marx se pergunta então: o que significaria "fruto do trabalho", o que seria uma "distribuição justa", e se "a todos os membros da sociedade" significaria também aos que não trabalham?

Marx (2012, p. 31) esclarece que o fruto do trabalho não pode ser entregue a cada trabalhador, mas, sim, o valor correspondente à "soma das horas individuais de trabalho" na forma de certificados que podem ser trocados por produtos necessários nos estoques sociais.

Do "produto social total" haverá a necessidade de ocorrer deduções para a constituição de variados fundos coletivos. Podemos distinguir primeiramente esses fundos em dois: os voltados para produção e aqueles voltados para o consumo. Ainda podemos categorizá-los em três: necessidades econômicas (produção), necessidades da administração, que não entram diretamente na produção (gestão ou burocracia, na falta de palavra melhor) e necessidades coletivas (serviços sociais, seguridade).

As necessidades da produção envolvem: "recursos para a substituição dos meios de produção consumidos", "para a expansão da produção", "fundo de reserva ou segurança contra acidentes, prejuízos causados por fenômenos naturais, etc." (Marx, 2012, p. 29). Marx (2012, p. 29) observa que essas deduções "são uma necessidade econômica", mas que "elas não podem de modo algum ser calculadas com base na justiça”.

As outras deduções do produto social são voltadas ao consumo: a) "custos gerais da administração, que não entram diretamente na produção" (Marx, 2012, p. 29); b) necessidades coletivas: escolas, serviços de saúde, "fundos para as incapacidades para o trabalho etc., em suma, 
para o que hoje forma a assim chamada assistência pública à população carente" (Marx, 2012, p. 30).

Ao examinar a relação entre direito, igualdade e justiça, Marx (2012, p. 31-33, grifo do original) estabelece que o "igual direito" na primeira fase da sociedade comunista ainda prevalecerá, pois que corresponde à herança do "direito burguês", de uma noção de que "o direito dos produtores é proporcional a seus fornecimentos de trabalho". Tal noção de igualdade é reformulada por Marx, já que os indivíduos são desiguais nas suas capacidades, condições e necessidades, descrevendo o que nomeamos como equidade. Porém, assume que "o direito nunca pode ultrapassar a forma econômica e o desenvolvimento cultural, por ela condicionado, da sociedade" (Marx, 2012, p. 32-33), ou seja, só com o desenvolvimento de uma nova cultura e com a abundância ${ }^{1}$ produtiva se terá "de cada um segundo suas capacidades, a cada um segundo suas necessidades” (Marx, 2012, p. 33), e quando isso ocorrer, alcançar-se-á a fase superior da sociedade comunista. ${ }^{2}$

Marx (2012, p. 43) faz-se questionamentos-chave: "por que transformações passará o ordenamento estatal numa sociedade comunista?”. "Quais funções sociais, análogas às atuais funções estatais, nela permanecerão?" Responde que entre o capitalismo e o comunismo, há "um período político de transição, cujo Estado não pode ser senão a ditadura revolucionária do proletariado".

Essas menções até aqui podem nos ajudar a entender o contraste entre estas duas formas políticas de Estado: o Estado burguês e o Estado proletário na sua primeira fase.

1 “Marx chama a esta primeira etapa da nova sociedade 'o estágio inferior do comunismo'. Distinguia-o assim do estágio superior onde desapareceria, ao mesmo tempo que o último espectro da necessidade, a desigualdade material" (Trotsky, 1980, p. 37).

2 "A princípio, o Estado operário não pode ainda a cada um trabalhar 'segundo as suas capacidades', o que significa fazer, o que quiser e puder, nem recompensar cada um 'segundo as suas necessidades', independentemente do trabalho fornecido. $O$ interesse do crescimento das forças produtivas obriga a recorrer às habituais normas do salário, isto é, à repartição de bens segundo a quantidade e a qualidade do trabalho individual" (Trotsky, 1980, p. 36-37). 


\subsection{A tradição marxista consolidada em Lenin: todo poder aos sovietes!}

Lenin pode ser considerado um dos grandes responsáveis pela consolidação de uma tradição marxista da teoria do Estado. Em 1917, 34 anos após a morte de Marx, duas revoluções russas no mesmo ano para consolidar a direção da nova sociedade, Lenin procura reunir em O Estado e a revolução toda a concepção de Marx e Engels sobre o Estado e a lição de que não basta se apoderar dele, mas que toda sua máquina administrativa tem de ser abolida e/ou substituída "pelos Soviéts dos deputados operários e seus homens de confiança” (Volin, 1950). Nas “Teses de Abril”, documento voltado aos bolcheviques, "Lênin lançou a palavra de ordem 'Todo o poder aos Soviéts'”, a forma de organização em conselhos do proletariado (Volin, 1950). Porém, e essa é uma noção essencial para este trabalho, o Estado como força administrativa e repressiva - ou até mesmo burocrática, especialmente no socialismo real — não cessa de vez, mas se extingue.

A grande diferença de ganhos societários quanto à restituição da liberdade ou emancipação humana seria que "o governo sobre as pessoas dá lugar à administração das coisas e à direcção das operações de produção. O Estado não é abolido, extingue-se", diz Engels (Lenine, [19--], p. 20). ${ }^{3}$ Essa esperança de Engels (assumida por Lenin) ainda carrega a formulação lógica de que "o primeiro acto do Estado em que ele aparece realmente como representante da sociedade inteira - a apropriação dos meios de produção em nome da sociedade - é, ao mesmo tempo, o seu último acto como Estado" (Lenine, [19--], p. 20). ${ }^{4}$

Duas lições conceituais importantes aqui é que a ação de abolir diverge do processo de se extinguir. Nas palavras de Lenin ([19--], p. 21): “O Estado burguês, segundo Engels, não se extingue - é abolido pelo proletariado no decurso da revolução. $O$ que se extingue depois desta revolução é o Estado proletário, ou, por outras palavras, um meio-Estado".

3 ENGELS, Friedrich. Anti-Dühring. Paris: Edições Sociais, 1956. p. 319.

4 Idem, ibidem. 
O termo "adormecimento" (Lenine, [19--], p. 22) é utilizado para explicar o que deverá ocorrer com a forma política da ditadura do proletariado, a fase da "democracia mais completa" (Lenine, [19--], p. 22).

Provocar uma revolução era uma das tarefas pretendidas por Marx às organizações do proletariado ou voltadas ao proletariado, as quais podemos chamar genericamente de partido. Uma vez instalada a revolução, ela deve, se bem dirigida, provocar um processo de transição para uma nova mentalidade que se materialize em novas relações sociais. A boa direção a que nos referimos depende da abolição da máquina do Estado, o que significa abolir a forma política da democracia parlamentar (ou representativa) burguesa. Tal abolição pede, na verdade, uma substituição da forma política: a ditadura do proletariado. Esta, sim, visa à ação da autoextinção tanto da necessidade do Estado quanto da própria democracia, pois ainda temos um meio Estado nessa primeira fase da sociedade comunista.

Para Lenin, essa fase ainda carrega um "poder especial de repressão", ${ }^{5}$ pois o próprio Estado é a força que permite que esse poder seja exercido, o qual tem a finalidade, através da substituição do exército permanente e da polícia do Estado burguês pelas milícias armadas do Estado proletário, da "apropriação dos meios de produção pela sociedade" (Lenine, [19--], p. 21). A crítica, portanto, a qualquer "estado em geral" (Lenine, [19--], p. 23) é distinta da dos "oportunistas" a que Lenin se referia, os sociais-democratas ou reformistas, e muito mais realista quanto à posição dos anarquistas, os quais tinham dificuldade de enxergar a necessidade estratégica de fazer uso de um "meio estado" nem que fosse durante um período de transição desencadeado por uma revolução: "Nós não podemos conceber uma democracia, mesmo uma democracia proletária, sem órgãos representativos; mas podemos e devemos concebê-la sem parlamentarismo", disse Lenin ([19--], p. 54), ou seja, órgãos representativos são necessários a essa nova democracia, não podendo ser concebida exclusivamente por democracia direta.

5 Gramsci também concordava com algum nível de coerção estatal nessa fase. Denominava essa função de Estado guarda-noturno. 
Sobre o funcionalismo público, Lenin ([19--], p. 55) disse:

Não se trata de suprimir um golpe, em toda a parte e completamente, o funcionalismo, [...)] mas destruir de um golpe a velha máquina administrativa para começar [...] a construir uma nova, permitindo suprimir gradualmente todo o funcionalismo.

E continua Lenin ([19--, p. 56) explicando como a produção se organizará a partir do "meio Estado”:

Seremos nós mesmos, os operários, que organizaremos a grande produção, partindo daquilo que já foi criado pelo capitalismo, apoiando-se na nossa experiência operária, estabelecendo uma disciplina rigorosa, uma disciplina de ferro, mantida pelo poder do Estado dos operários armados.

Ao vaticinar o estabelecimento de "uma disciplina rigorosa", o papel coercitivo do "meio Estado" pode ganhar relevância. Mais do que simplesmente explorarmos uma forma política, devemos analisar as crenças dos desdobramentos tanto sociais quanto da produção, as quais previam, por exemplo, que:

[...] as funções de fiscalização e de contabilidade, cada vez mais simplificadas, serão desempenhadas por toda a gente, alternadamente, até se tornarem um hábito e até desaparecerem, por fim, como funções específicas de uma categoria especial de indivíduos (Lenine, [19--], p. 56-57).

A extinção do funcionalismo, de modo gradual, dependia desses desdobramentos. Essa “categoria especial de indivíduos” abrange a separação entre trabalho manual e intelectual, privilegiando uns economicamente e estigmatizando outros.

Compreendemos até agora que a noção de uma sociedade de "operários associados" (Lenine, [19--], p. 57) vai assim tomando o lugar de um governo que se coloca acima dos interesses ou da vontade expressa 
desses operários, substituindo o corpo do funcionalismo ou da burocracia do Estado.

Porém, para Trotsky — em sua análise publicada em 1936 do andamento da Revolução Russa, culpando especialmente a liderança de Stalin pelos resultados à frente do partido -, foi justamente a etapa que não se efetivara, gerando não um capitalismo de Estado, segundo Trotsky, mas uma "casta" burocrática que concentrou o poder político e a direção da produção, impedindo o processo de desenvolvimento do trabalho livre, o princípio fundador do marxismo.

Naquele meio Estado stalinista, para Trotsky (1980, p. 167), o operário "dificilmente se poderá sentir um 'trabalhador livre'. O funcionário é para ele um chefe, o Estado, um patrão. $O$ trabalho livre é incompatível com a existência do Estado burocrático".

\section{Estado ou transição?}

O antistalinista Trotsky, já em exílio, forçado a se afastar da direção da experiência soviética, chegou a prever a possibilidade de um retorno ao capitalismo (Trotsky, 1980, p. 176) caso uma revolução política (Trotsky, 1980, p. 175) não corrigisse os rumos da revolução social, pois, segundo Trotsky (1980, p. 198), "nunca se viu o diabo cortar as garras por sua própria vontade". Opinião que prevaleceu a respeito da necessidade de uma revolução violenta empregada anteriormente sobre a burguesia, "porque não há outras classes nem outros meios que possam quebrar a resistência dos capitalistas exploradores”, disse Lenin ([19-], p. 100, grifos do original).

Uma revolução contraburguesa, para conduzir a sociedade a um fim determinado de modo consciente, não sem um longo e difícil processo de adaptação e resistência, traz inevitavelmente a necessidade de outra forma política. Tudo é política, analisou Gramsci (Coutinho, 1992, p. 52). Gramsci se referia à política em sentido amplo, como observa Coutinho (1992, p. 52-55), não à sua defesa em sentido estrito, como a forma política 
que vem sendo institucionalizada pela democracia burguesa na sua versão representativa. Lenin chegou a recorrer a um dos primeiros pontos da teoria da evolução, "da ciência em geral", para dizer que "historicamente deve sem dúvida alguma existir um estádio particular ou uma etapa particular de transição do capitalismo para o comunismo" (Lenine, [19-], p. 97-98).

Os conselhos a partir da reunião dos operários de fábrica, liderando e pautando tanto os partidos quanto os sindicatos, chegaram a ser, assim como na pretendida república dos sovietes de Lenin, a grande fórmula de organização pretendida por Gramsci para liderar na Itália o processo de ruptura com a forma política burguesa.

Malgrado a experiência da virada para os anos 20 do século passado em Turim, quando um núcleo de conselhos de fábrica malogrou na sua ação de assumir a produção e foi-se assim evidenciando para Gramsci que um processo de formação de hegemonia que confronte a burguesia deve coexistir para apoiar o operariado grevista (Coutinho, 1992, p. 1820), os conselhos, como maneira de participação formal dos diversos segmentos da sociedade na esfera estatal, podem passar a representar o aprofundamento da democratização.

Apesar de que para a tradição marxista nenhum Estado seja livre ou popular, "nós somos partidários da república democrática por ser a melhor forma de Estado para o proletariado em regime capitalista", disse Lenin ([19--], p. 23).

Ao final da década de 70 do século passado, em meio a campanhas pela redemocratização do Brasil, Coutinho (1979, p. 34) dizia que a visão de que a democracia política não seria mais que uma nova forma de dominação da burguesia, dos monopólios nacionais e internacionais, era uma visão estreita proveniente de uma concepção equivocada da teoria marxista do Estado, "numa falsa e mecânica identificação entre democracia política e dominação burguesa”. Coutinho (1979, p. 35) defendia que o que se tinha pela frente com a redemocratização era uma tarefa árdua de combate em longo prazo "pela criação dos pressupostos políticos, econômicos e ideológicos que tornarão possível o estabelecimento e a consolidação do socialismo em nosso País". 
Devemos lembrar que onde existe democracia existe o Estado em geral, e que apesar de só no comunismo ela poder se realizar como "uma democracia realmente completa", segundo a tradição marxista, "quanto mais completa ela for, mais depressa se tornará supérflua e se extinguirá por si própria" (Lenine, [19--], p. 100-102). Podemos compreender daí que essa fase seria o autêntico e completo não Estado.

Em Para além do capital, Mészáros (2011) apresentou importantes reflexões sobre a necessidade de uma teoria da transição para o socialismo. Ele apresenta três pontos a serem tratados necessariamente em conjunto: (i) refletir sobre a proposição de uma alternativa viável "além do capital", mas com metas realistas; (ii) estimular uma "ofensiva socialista" a partir da atualidade histórica e com as instituições existentes do movimento operário; e (iii) considerar uma "política radical" que contraste com as meras reestruturações econômicas (Mészáros, 2011, p. 1064).

Ao elaborar sobre a oportunidade que cria as condições para uma transição sem o uso de modos ditatoriais, uma grande crise econômica ou estrutural foi compreendida como o momento permissivo, mas mesmo assim com uma janela aberta bem estreita e por tempo limitado.

Segundo Mészáros (2011, p. 1076-1078), reestruturar a economia é uma tarefa político-social, o que "significa igualmente reestruturar a sociedade". A grande crise "abre uma brecha razoável na ordem estabelecida". Mészáros diz que "tais brechas podem ser alargadas a serviço da reestruturação social”, ou fechadas no interesse da sobrevivência do capital. Afirma ele que "somente uma iniciativa política pode influir na brecha".

Porém, as crises são comumente apresentadas como econômicas, e desde o instante em que medidas nesse sentido favoreçam algum horizonte de melhora, as causas sociais permanecem obscurecidas e dá-se uma revitalização do capital. Assim, o momento da "política radical" tem sua janela fechada.

Mészáros (2011, p. 1077) então prega que "somente uma autodeterminação radical da política pode prolongar o momento da política radical". A solução surgiria "por meio da reestruturação dos poderes de tomada de decisão” (Mészáros, 2011, p. 1077). Essa política radical 
"precisa transmitir, no auge da crise, as suas aspirações" ao seu próprio meio político, em vez de lutar contra ele, "na forma de efetivos poderes de tomada de decisão” (Mészáros, 2011, p. 1078).

Essa transferência de poder político só é possível na grande crise estrutural, e ela será reversível se as medidas não corresponderem a um sucesso econômico. E mesmo no sucesso da reestruturação econômica, passada a crise, a política radical deve ter bases complementares nas "áreas e formas de ação extraparlamentar" (Mészáros, 2011, p. 1078) ou, provavelmente, será forçada a recuar frente à ofensiva das forças políticas tradicionais.

Essas foram as reflexões meszarianas, em síntese, para uma teoria da transição e o pleno aproveitamento de uma política radical, as quais não podem prescindir de propostas para além da reestruturação econômica, e de metas viáveis para a formação e o apoio de uma hegemonia socialista.

Vê-se nisso a aplicação da noção de hegemonia gramsciana para a tomada ou manutenção de poder envolvendo uma ofensiva socialista. Em Gramsci, a crise de hegemonia também é a oportunidade de tomada de poder (Coutinho, 1992, p. 93), apesar de que sem uma contra-hegemonia articulada a ordem burguesa pode ser relativamente bem estabilizada pelos aparelhos coercitivos e pelos meandros burocráticos e normativos, embora com alterações na composição do poder que, no entanto, não alteram o modo de produção.

Como poderíamos responder a uma ligação entre a teoria do Estado e a teoria da transição de Mészáros? A transição se dá a partir do Estado e das condições históricas de desenvolvimento econômico, sociocultural, ideológico e até jurídico-normativo. Mesmo enfraquecido, o Estado mantém sua dominação, o poder político e coercitivo, mas pode vir a perder sua direção ideológica e com ela a hegemonia. Estamos aqui fazendo referência à teoria da supremacia do Estado, ou de uma classe sobre as outras, em Gramsci. Entretanto, um dos fatores-chave é ter de pronto uma hegemonia socialista que possa confrontar e substituir a do poder dominante, caso contrário até outras ideologias menos democráticas podem disputar o poder político. 
O Estado com traços feudais, retratado por Marx, alargou-se, como na elaboração gramsciana, a qual vê não apenas coerção, tal como se destacava em Marx, mas também consenso. O Estado através da sua superestrutura, da democracia parlamentar e representativa, fornece instrumentos conciliatórios entre as classes. Todavia, não tem capacidade prática de transformação radical da realidade, pois esta se encontra condicionada, segundo a crítica marxista da sociedade do capital, à própria organização socioeconômica.

Ainda assim, o uso da democracia é hoje o único instrumento, tirando uma quebra radical e inesperada da ordem capitalista, neste Estado ampliado que quer se afastar do papel social estando cada vez mais presente na manutenção da institucionalidade democrática. Seguindo as pistas de Mészáros, uma crise da legitimidade democrática pode favorecer reivindicações por aprofundamento da democracia via mais participação direta, ou seja, a disputa democrática deve se referir também à sua própria expansão como forma política, mesclando representatividade com participação direta via conselhos, por exemplo.

Pelo desenho constitucional de 1988, podemos falar em participação popular e controle social (Siraque, 2004, p. 124-126), mas os mecanismos são ainda muito ineficazes, pouco estimulam ou permitem de modo muito limitado a participação e controle sociais, dando na prática o grosso do poder normativo aos legisladores via o sistema de representatividade do voto, e também o grosso do poder da administração ao executivo, com fortes impasses em que a participação direta praticamente não atua. Desde a vigência constitucional, por exemplo, apenas quatro projetos de iniciativa popular viraram leis no congresso nacional (Calgaro, 2017), pelo menos até fevereiro de 2017.

As reivindicações populares têm que ser organizadas também por projetos concretos liderados por uma política radical das formas organizativas, pois até o recuo do estágio democrático atual é possível se não houver uma contra-hegemonia burguesa preparada para lidar com os próprios instrumentos normativos da superestrutura. 
Revoltas populares esparsas ou greves sem conexão consciente entre si são sintomas da falta de unidade das classes subalternizadas. 0 cenário atual necessita tanto de movimentação da sociedade civil quanto de lideranças que agreguem em torno de si diferentes movimentos por justiça e conquista de direitos. Porém, as reformas se concretizam por dentro da própria ordem jurídico-normativa. Assim, essas lideranças passam necessariamente pelo partido político, o único capaz de manipulação por dentro da política estrita criticada por Gramsci - sem prescindir daqueles que pedem por transformações radicais para além do capital.

\section{Considerações finais}

A busca da superação do Estado como forma política de opressão na tradição marxista é tão grande que Engels chegou a sugerir, à época do programa da fusão dos partidos operários na Alemanha do qual Marx diverge em Crítica do programa de Gotha, que o termo fosse substituído por comunidade (Lenine, [19--], p. 95).

Para Bobbio (1998), "a teoria marxista do Estado é uma teoria do modo como se conquista o poder, não do modo como se o exerce, enquanto que o liberalismo é sobretudo uma teoria do exercício do poder".

A crítica marxista à apropriação privada da produção enfatizou que o desenvolvimento do exercício do poder dependeria da apropriação do produto social, se ela seria privada ou coletiva. Neste último caso, a própria coletividade deveria criar tanto o modo quanto o conteúdo das decisões a partir desse tipo de sociabilidade, especialmente como uma ruptura consciente da organização socioeconômica da sociedade do capital.

A democracia desenvolveu-se a partir de enormes restrições inclusivas, a introdução de demandas democráticas não foi uma conquista integral do liberalismo nem ele foi um campo homogêneo (Coutinho, 1999). $O$ exercício do poder de Estado vem sendo um modo processual de construção de normas, ainda que sob a forte mentalidade do direito à propriedade e da exploração que isso gera. 
Se o socialismo é ou não uma forma estatal, se será necessariamente uma mera administração das coisas e da produção, sem ser um governo sobre as pessoas, como queria Engels, parece que a história já tratou de negar. Porém, a história revelou que o socialismo tendeu a uma burocratização, não à formação de classes econômicas, ou seja, o exercício do poder derivou da posição na burocracia e não da força da acumulação, segundo Trotsky (1980), pela análise do caso da URSS.

Duas conclusões oferecemos: (i) mesclar mais formas de participação, em especial via conselhos, à forma representativa atual, pode ser um modo de reatualizar a sociedade, pois negar o aprofundamento da democracia ou outras formas políticas de Estado implica evidente receio da soberania popular, declarada na Constituição de 1988; (ii) as crises são oportunidades para novas concepções de política radical, assim denominada por Mészáros, as quais ultrapassam as meras propostas econômicas.

\section{Referências}

BOBBIO, Norberto. O saldo vermelho. [Entrevista cedida a] Giancarlo Bosetti. Tradução: Roberta Barni. Folha de S.Paulo, São Paulo, 24 maio 1998.

BOITO JR., Armando (org.). A Comuna de Paris na história. São Paulo: Xamã, 2002.

CALGARO, Fernanda. Em quase 30 anos Congresso aprovou 4 projetos de iniciativa popular. Portal G1, Brasília, 18 fev. 2017. Política.

COUTINHO, Carlos Nelson. A democracia como valor universal. In: SILVEIRA, Ênio et al. Encontros com a civilização brasileira. Rio de Janeiro: Civilização Brasileira, 1979.

COUTINHO, Carlos Nelson. Gramsci: um estudo sobre seu pensamento político. Rio de Janeiro: Campus, 1992.

COUTINHO, Carlos Nelson. Cidadania e modernidade. Perspectivas, São Paulo, n. 22, p. 41-59, 1999.

ENGELS, Friedrich. Prefácio de Engels de 6 de janeiro de 1891. In: MARX, Karl. Crítica do programa de Gotha. São Paulo: Boitempo, 2012.

HOBSBAWM, Eric. A diferença do holocausto. [Entrevista cedida a] Giancarlo Bosetti. Tradução: Roberta Barni. Folha de S.Paulo, São Paulo, 24 maio 1998. 
LENINE, Vladimir I. O Estado e a revolução. Tradução: J. Ferreira. [S. l.]: [s. n.], [19-]. Disponível em: http://lutasocialista.com.br/livros/LENIN/. Acesso em: 6 maio 2021.

LÖWY, Michel. Prefácio à edição brasileira. In: MARX, Karl. Crítica do programa de Gotha. São Paulo: Boitempo, 2012.

MARX, Karl. A guerra civil na França. São Paulo: Ridendo Castigat Mores, 1999. Disponível em: http://www.ebooksbrasil.org/adobeebook/guerracivil.pdf. Acesso em: 20 maio 2021.

MARX, Karl. Crítica do programa de Gotha. São Paulo: Boitempo, 2012. Disponível em: http://www.afoiceeomartelo.com.br/. Acesso em: 20 maio 2021.

MERRIMAN, John. A Comuna de Paris: 1871: origens e massacre. Rio de Janeiro: Anfiteatro, 2015.

MÉSZÁROS, István. Política radical e transição para o socialismo. In: MÉSZÁROS, István. Para além do capital: rumo a uma teoria da transição. São Paulo: Boitempo, 2011. Disponível em: https://files.cercomp.ufg.br/weby/up/208/o/para-alem-do-capital. pdf. Acesso em: 18 maio 2021.

SIRAQUE, Vanderlei. O controle social da função administrativa do Estado: possibilidades e limites na Constituição de 1988. 2004. Dissertação (Mestrado em Direito) — Pontifícia Universidade Católica, São Paulo, 2004.

TROTSKY, Leon. A revolução traída. São Paulo: Global, 1980.

VOLIN, B. M. As Teses de Abril de Lênin. Problemas: revista mensal de cultura política, n. 25, mar./abr. 1950. Disponível em: https://www.marxists.org/portugues/tematica/ rev_prob/25/teses.htm. Acesso em: 18 maio 2021.

\section{Sobre os autores}

Marcus Paulo Eiffle Duarte - Mestrando em Política Social e graduado em Serviço Social.

E-mail: marcus.paulo2010@gmail.com

Patrícia Baptista Barreto - Mestranda em Política Social. Assistente social. E-mail: mcpatriciabaptista@yahoo.com.br

Luci Faria Pinheiro - Doutora em Antropologia e Sociologia Política. Professora associada.

E-mail: lucifariapinheiro@gmail.com 